\title{
Perkembangan Mutiara Mabé pada Pinctada margaritifera di Perairan Arakan, Sulawesi Utara
}

\section{(The Development of Mabé Pearl from Pinctada margaritifera in Arakan waters, North Sulawesi)}

\author{
Khesyia A. Makhas ${ }^{1^{\star}}$, N. Gustaf F. Mamangkey ${ }^{1}$, Desy M. H. Mantiri ${ }^{1}$
}

1. Program Studi IImu Kelautan, Fakultas Perikanan dan IImu Kelautan, Universitas Sam Ratulangi, Manado *e-mail : khesyia.abigail@gmail.com

Pinctada margaritifera is the pearl oyster species that generally produce black pearls. In North Sulawesi, this species occupies lagoon areas in Arakan, South Minahasa District. One type of pearls that can be produced from this species are mabe pearls. However, scientific studies based on the structure and the elemental compsitions of the produced pearls from $P$. margaritifera in Arakan waters has never been done. The purpose of this study was to assess the thickness of the pearls over the time and to describe aragonite structures composing the pearls. This research was carried out for seven months with three sampling times $\left(2^{\text {nd }}, 6^{\text {th }}\right.$ and $\left.7^{\text {th }}\right)$. Prior to this, half-round plastic nuclei were inserted (glued) into the internal part of the shell of $P$. margaritifera. The development of pearl layers were oberved under stereo microscope and Scanning Electron Microscope (SEM). The average thickness of the pearls from the second, sixth and seventh month are $0.201,1.026,0.914 \mathrm{~mm}$, respectively. While the average thickness of the aragonite platelets from the second and six month are 0.511 and $0.604 \mu \mathrm{m}$, respectively.

\section{Keyword : Pinctada margaritifera, Mabé Pearl, Pearl Structure}

Pinctada margaritifera adalah spesies kerang mutiara yang umumnya menghasilkan mutiara berwarna hitam sehingga dikenal sebagai mutiara hitam. Di Sulawesi Utara, spesies ini banyak menempati daerah laguna di perairan Arakan, Kabupaten Minahasa Selatan. Salah satu jenis mutiara yang bisa diproduksi dari spesies kerang ini adalah mutiara jenis mabé. Namun, kajian ilmiah tentang struktur dan senyawa mutiara yang dihasilkan dari kerang $P$. margaritifera yang berasal dari perairan Arakan belum pernah dilakukan. Tujuan dari penelitian ini adalah untuk mengetahui tingkat ketebalan lapisan mutiara jenis mabé berdasarkan pertambahan waktu dan mendeskripsikan bentuk struktur pada lapisan mutiara jenis mabé berdasarkan pertambahan waktu. Penelitian ini dilakukan selama tujuh bulan dengan tiga kali masa sampling yaitu pada bulan kedua, keenam dan ketujuh. Pada bulan awal dilakukan penyisipan/penempelan inti mutiara setengah bulat berbahan plastik pada dinding bagian dalam dari cangkang kerang $P$. margaritifera. Pertumbuhan lapisan diamati dengan mikroskop stereo dan Scanning Electron Microscope (SEM). Hasil pengamatan yang didapat adalah tebal rata-rata lapisan mutiara bulan kedua adalah 0,201 $\mathrm{mm}$, bulan keenam adalah $1,026 \mathrm{~mm}$ dan $0,914 \mathrm{~mm}$ pada bulan ketujuh. Berdasarkan analisis SEM menunjukkan bahwa struktur bangunan lapisan mutiara seperti susunan batu bata dengan ukuran platelet aragonite rata-rata pada bulan kedua adalah $0,511 \mu \mathrm{m}$ dan pada bulan keenam adalah $0,604 \mu \mathrm{m}$.

Kata kunci : Pinctada margaritifera, Mutiara Mabé, Struktur Mutiara 


\section{PENDAHULUAN}

Keindahan mutiara telah mempesona manusia sejak zaman dahulu kala; menjadikannya sebagai simbol kekuasaan, kemewahan dan perkembangan peradaban (Strack, 2008). Beberapa spesies kerang mutiara dari genera Pinctada dan Pteria merupakan penghasil mutiara dan banyak digunakan sebagai perhiasan. Kerang mutiara dari kedua genera ini merupakan jenis kerang mutiara yang paling banyak dibudidaya untuk menghasilkan mutiara (Southgate dkk., 2008). Secara spesifik, spesies kerang mutiara yang banyak dibudidaya adalah Pinctada fucata, $P$. maxima, $P$. margaritifera dan Pteria penguin. Keempat spesies ini banyak tersebar di kawasan Indo-Pasifik, mulai dari perairan Samudera Hindia sampai di Samudera Pasifik termasuk perairan Indonesia (Wada dan Tëmkin, 2008). Kerang mutiara bibir hitam, Pinctada margaritifera adalah salah satu spesies dari genus Pinctada yang banyak digunakan untuk memproduksi mutiara hitam baik bulat maupun setengah bulat di wilayah Indo-Pasifik (Tisdell dan Poirine, 2000 dalam Linard dkk., 2011; Ellis dan Haws, 1999).

Jenis mutiara hasil kegiatan budidaya yang banyak diproduksi adalah dari jenis mutiara bulat dan mutiara setengah bulat (blister atau mabé) (Southgate dkk., 2008). Mutiara bulat adalah mutiara yang terbentuk dari inti yang dimasukkan ke dalam gonad sementara mutiara setengah bulat adalah mutiara yang disisipkan/dilekatkan pada cangkang bagian dalam dan menghadap mantel. Namun, informasi ilmiah tentang pembentukan mutiara di Indonesia masih langka apalagi secara spesifik pada mutiara jenis setengah bulat atau mabé.

$P$. margaritifera adalah kerang yang umumnya menempati zona litoral dan sublitoral pada daerah terumbu karang, juga pada daerah laguna di daerah tropis (Wada dan Tëmkin, 2008; Yukihara, dkk., 1999) seperti di perairan Arakan, Sulawesi Utara. Namun demikian, potensi kerang ini untuk menghasilkan mutiara dari perairan Arakan, sejauh ini belum pernah dikaji. Terdapat lima faktor analisis kualitas mutiara yaitu: kilau, warna, ukuran, bentuk dan kekasaran permukaan (Taylor dan Strack, 2008). Penunjang kelima faktor tersebut di antaranya adalah dari struktur bangunan lapisan mutiara. Pada penelitian ini diharapkan akan mendapatkan deskripsi penunjang kualitas berdasarkan ketebalan dan struktur salah satu jenis mutiara yaitu mutiara setengah bulat atau mabé yang terbentuk setelah disisip inti setengah bulat berbahan plastik.

\section{METODE PENELITIAN}

Sampel Pinctada margaritifera dikumpulkan dari perairan laut sekitar Desa Arakan, Kecamatan Tatapaan, Kabupaten Minahasa Selatan (Gambar 3). Sampel diambil pada bulan kedua, keenam dan bulan ketujuh setelah penyisipan inti mutiara. Dikarenakan keadaan lingkungan, maka pengambilan sampel pada bulan ke-3, 4 dan 5 tidak dapat dilakukan. Koleksi kerang $P$. margaritifera dilakukan dari sekitar perairan di Desa Arakan, sebanyak 20 kerang; 10 kerang kontrol dan 10 kerang uji. Pemilihan kerang $P$. margaritifera yang akan disisip inti mutiara dilakukan berdasarkan ukuran kerang yang sama dengan rata-rata $( \pm S D)$ dorso-ventral $8,75 \pm 0,79 \mathrm{~cm}$. Kerang disisip dengan inti mutiara yang berbahan plastik dan berbentuk setengah bulat, dengan cara melekatkan inti mutiara ke cangkang bagian dalam setiap individu kerang. Kerang yang sudah selesai disisip inti mutiara dilabel, kemudian dimasukkan ke dalam 'pocket net'. Setelah itu 'pocket net' dibawa menggunakan perahu untuk diikatkan pada rumpon. 'Pocket net' ditempatkan pada kedalaman $4 \mathrm{~m}$ dari permukaan laut.

Pengukuran Ketebalan Lapisan
Mutiara




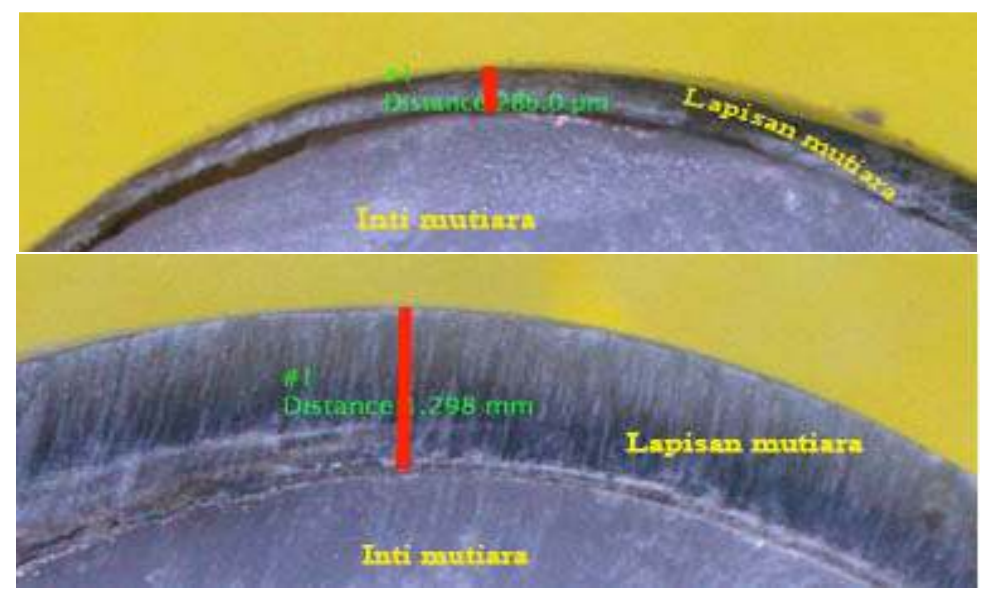

Gambar 1. Lapisan mutiara yang makin menebal seiring pertambahan waktu (Atas: lapisan mutiara pada bulan kedua; Bawah, lapisan mutiara pada bulan keenam).

Mutiara diambil dari cangkang dengan cara memotong bagian tepi mutiara sehingga menyisakan bagian setengah bulat. Mutiara kemudian dibelah dua secara simetris dengan memotong bagian mutiara tersebut secara vertikal, setelah itu, bagian yang dipotong dengan menggunakan bor kemudian diukur ketebalannya (dalam $\mathrm{mm}$ ) menggunakan mikrosop stereo di laboratoium Fakultas Perikanan dan IImu Kelautan.

\section{Analisis Struktur Bangunan Pada Lapisan Mutiara}

Analisisi struktur bangunan pada lapisan mutiara dilakukan dengan menggunakan SEM (Scanning Electron Microscope). Selanjutnya, setiap lapisan aragonite dihitung ratarata ketebalannya, dimana pengukuran dilakukan secara acak (dalam $\mu \mathrm{m}$ ).

\section{HASIL DAN PEMBAHASAN}

Kerang mutiara Pinctada margaritifera yang disisip/ditempel dengan material plastik berbentuk setengah bulat pada cangkang bagian dalam kerang, berhasil membentuk mutiara jenis mabé. Berdasarkan pengamatan visual dan pengukuran ketebalan lapisan mutiara yang dilakukan dengan menggunakan mikroskop stereo didapatkan bahwa lapisan mutiara telah terbentuk melapisi bagian plastik yang ditempelkan di cangkang. Lapisan mutiara yang membungkus material plastik setengah bulat ini mengalami peningkatan penebalan seiring dengan pertambahan waktu (Gambar 1). Walaupun terjadi penebalan dalam dua kali monitoring (bulan kedua dan keenam), namun peningkatan penebalan hanya sampai pada bulan ke enam, sementara data dari cangkang pada bulan yang ke tujuh menunjukkan penurunan tingkat ketebalan lapisan mutiara (Gambar 2). Ketebalan lapisan mutiara teramati pada bulan kedua, adalah $0.201 \mathrm{~mm}$, pada bulan keenam adalah $1.026 \mathrm{~mm}$ dan pada bulan ketujuh yaitu 0.914 $\mathrm{mm}$. Lapisan mutiara pada bulan

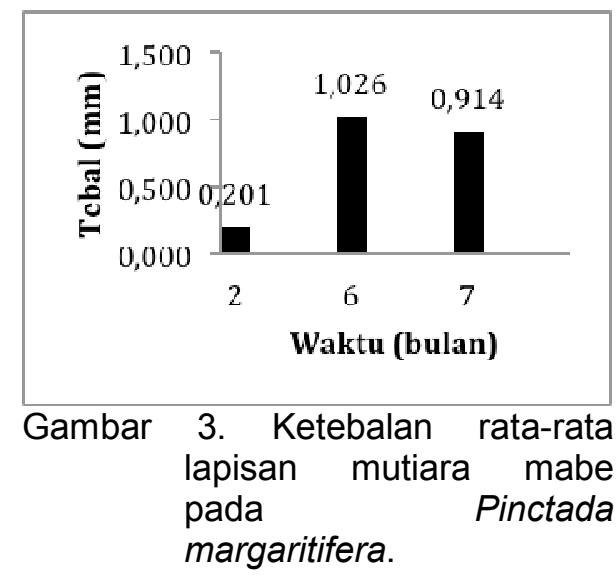



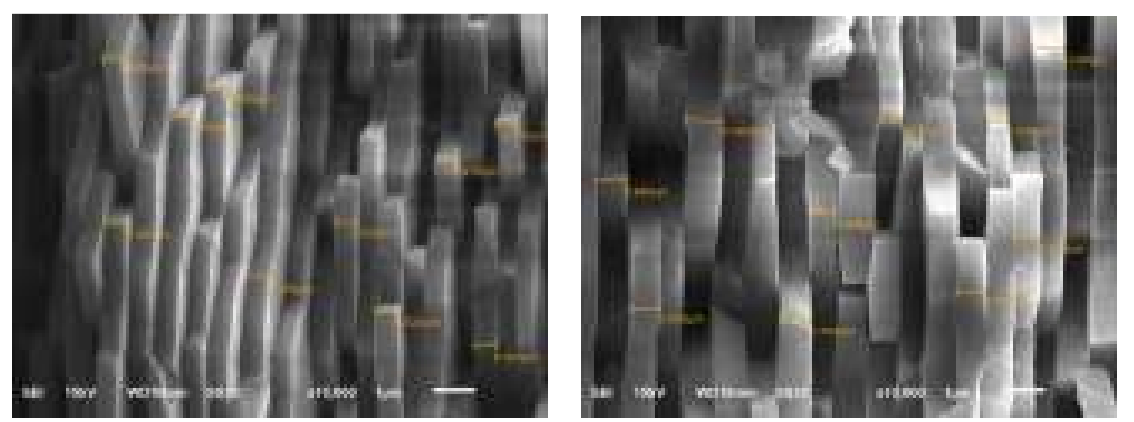

Gambar 3. Hasil SEM (Scanning Electron Microscope) dari lapisan aragonite yang menyusun lapisan mutiara (kiri) dan cangkang kerang (kanan) Pinctada margaritifera.

kedua sampai bulan keenam mengalami peningkatan penebalan, sedangkan pada bulan ketujuh, lapisan mutiara ternyata mengalami penurunan ketebalan. Fenomena ini diasumsikan terjadi akibat kerang yang digunakan sebagai kerang uji berasal dari induk yang berbeda dan memiliki umur yang bervariasi (Saucedo dan Southgate, 2008). Sehingga, ketika dilakukan sampling kerang pada bulan ketujuh dimungkinkan kerang tersebut memiliki umur yang jauh lebih tua daripada kerang yang disampling pada bulan-bulan sebelumnya. Dengan demikian, pada saat terjadi pelapisan terhadap inti pada kerang berumur tua akan mengalami kejenuhan dan cenderung bertumbuh lebih lambat (Schöne, dkk., 2005). Akibatnya lapisan nakreous pun tak banyak. Selain faktor umur kerang, faktor lain yang diasumsikan mempengaruhi ditemukannya kerang yang tidak menebal pada bulan ketujuh adalah akibat faktor lingkungan yang membuat kerang menjadi stress dan terhambat pertumbuhannya (Lucas, 2008; Saucedo dan Southgate, 2008).

\footnotetext{
Struktur bangunan pada lapisan mutiara yang dipindai (scanning) dengan menggunakan SEM (Scanning Electron Microscope) menunjukkan struktur seperti batu bata. Hal yang sama juga pada struktur bangunan dari cangkang pembentuknya (Gambar 3).
}

\begin{abstract}
Berdasarkan analisis SEM dan pengukuran platelet aragonite didapatkan bahwa pada bulan kedua rata-rata tebal lapisan aragonite pada mutiara adalah $0.511 \mu \mathrm{m}$ dan pada bulan keenam adalah $0.604 \mu \mathrm{m}$. Sedangkan rata-rata lapisan aragonite pada cangkang kerang pada bulan kedua, keenam dan ketujuh adalah $0.652 \mu \mathrm{m}, 0.842 \mu \mathrm{m}$ dan $0.539 \mu \mathrm{m}$ (Gambar 4). Data lapisan aragonite untuk mutiara pada bulan ketujuh tidak dapat disajikan karena ada kesalahan pemindaian dari laboratorium rujukan (Institut Teknologi Bandung).
\end{abstract}

Susunan menyerupai susunan batu bata yang terbentuk baik dalam pelapisan mutiara maupun pada bagian sisi dalam kerang dipercaya sebagai susunan lapisan aragonite (Addadi, dkk. 2006; Barthelat, dkk., 2007). Lapisan aragonite yang menyerupai batu bata ini melekat satu sama lain akibat adanya matriks protein (Barthelat dkk., 2007). Keteraturan ukuran dan bentuk dari setiap lapisan akan mempengaruhi difraksi cahaya yang masuk sehingga secara otomatis akan mempengaruhi tingkat kilau dari lapisan mutiara atau cangkang internal (Snow dan Pring, 2005). Berdasarkan data ukuran platelet aragonite didapatkan ukuran yang bervariasi, baik pada lapisan mutiara maupun pada lapisan internal (bagian dalam) cangkang. Terdapat juga perbedaan rata-rata ukuran platelet aragonite pada lapisan mutiara 


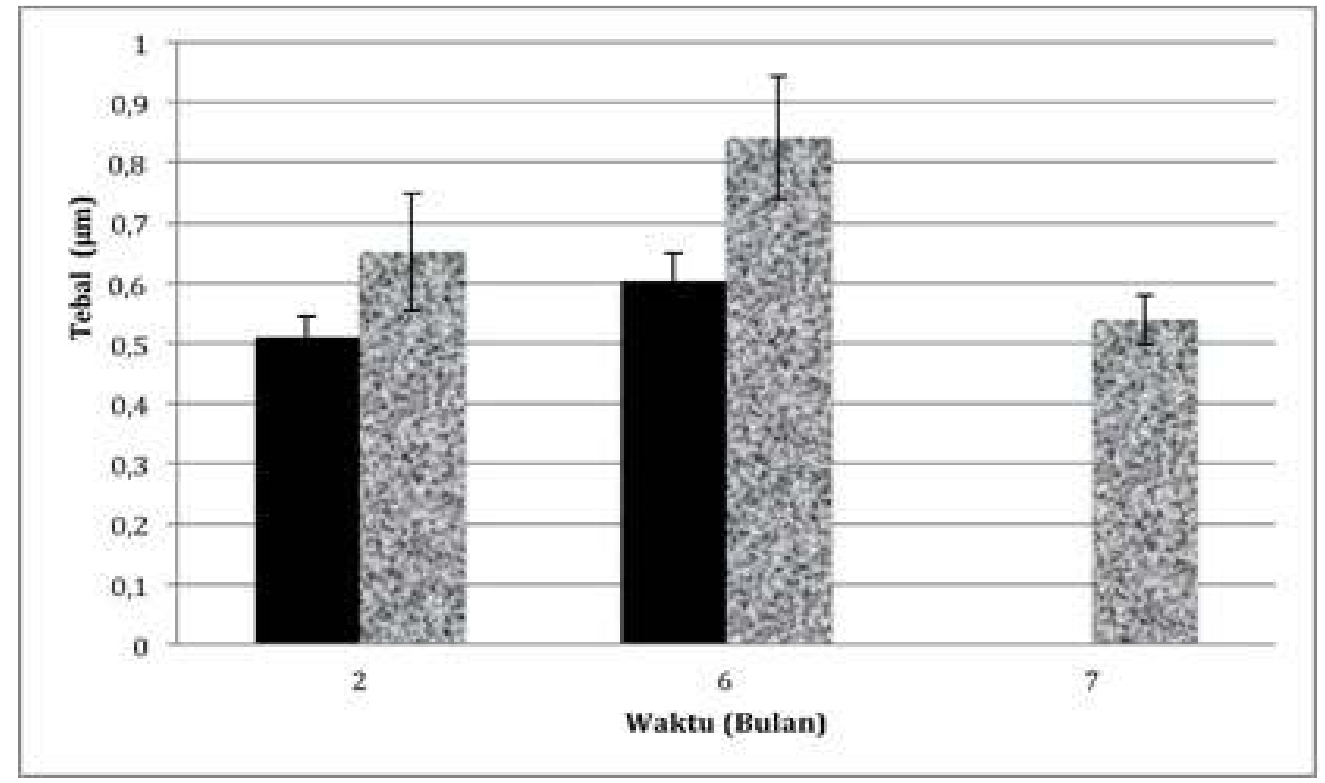

Gambar 4. Rata-rata ketebalan lapisan aragonite pada mutiara $\square$ dan cangkang kerang Pinctada margaritifera

dan lapisan internal cangkang, dimana lapisan aragonite pada mutiara cenderung memiliki ukuran yang lebih kecil. Sejauh ini belum ada studi yang mendetail untuk membandingkan antara lapisan aragonite pada mutiara mabe dan cangkangnya (yang tumbuh dalam satu individu). Namun perbedaan pertumbuhan lapisan atau ketebalan aragonite dimungkinkan pada spesies yang berbeda maupun pada kondisi lingkungan yang berbeda (Strack, 2006). Strack (2006) memaparkan lebih detail bahwa ketebalan platelet aragonite untuk mutiara hitam (Pinctada margaritifera) adalah dari 0.5 sampai $0.8 \mu \mathrm{m}$. Sementara ukuran platelet terkecil pada mutiara Akoya dari Pinctada fucata, $0.35-0.5 \mu \mathrm{m}$, dan yang terbesar pada mutiara air tawar 0.5 $1.8 \mu \mathrm{m}$.

Perbedaan tingkat ketebalan berdasarkan waktu sampling (umur bulan) menurut Gambar 4 dan terdapat peningkatan rata-rata penebalan baik pada mutiara maupun pada cangkang. Namun, peningkatan penebalan hanya terjadi pada bulan kedua dan keenam sedangkan pada bulan ketujuh ketebalan lapisan aragonite menurun. Kondisi ini (perbedaan ketebalan lapisan platelet aragonite) berhubungan erat dengan tingkat ketebalan lapisan mutiara (Sub Bab sebelumnya). Dimana ukuran platelet aragonite akan mengecil dan mempengaruhi ketebalan lapisan mutiara apabila diperhadapkan dengan kondisi ekstrim lingkungan atau berdasarkan usia kerang (Schöne, dkk., 2005, Lucas, 2008; Saucedo dan Southgate, 2008).

\section{KESIMPULAN}

Berdasarkan hasil yang diperoleh dari penelitian maka dapat ditarik kesimpulan bahwa:

1. Ketebalan lapisan mutiara mengalami peningkatan dari bulan kedua $(0.201 \mathrm{~mm})$ sampai bulan keenam $(1.026 \mathrm{~mm})$, tetapi mengalami penurunan ketebalan pada bulan ketujuh $(0.914 \mathrm{~mm})$.

2. Lapisan mutiara tersusun dari lapisan platelet aragonite yang menyerupai tumpukan batu bata dengan rata-rata ketebalan lapisan aragonite pada mutiara bulan kedua adalah $0.511 \mu \mathrm{m}$ dan pada bulan keenam adalah 0.604 $\mu \mathrm{m}$. 


\section{DAFTAR PUSTAKA}

Addadi, L., D. Joester, F. Nudelman dan S. Weiner. 2006. Mollusk Shell Formation: A Source of New Concepts for Understanding Biomineralization Processes. Wiley$\mathrm{VCH}$ Verlag $\mathrm{GmbH}$ dan Co. KGaA, Weinheim. Chem. Eur. J. 2006, 12, $980-987$.

Barthelat, F., H. Tang, P. D. Zavattieri dan H. D. Espinosa. 2007. On the mechanics of mother-of-pearl: A key feature in the material hierarchical structure. J ournal of the Mechanics and Physics of Solids 55 (2007) 306-337.

Ellis, S. dan M. Haws. 1999. Producing pearls using the Black-lip Pearl Oyster (Pinctada margaritifera). Center for Tropical and Subtropical Aquaculture Publication 141.

Linard, C. L., Y. Gueguenb, J. Moriceaua, C. Soyeza, B. Huia, A. Raouxa, J. P. Cuifd, J. C. Cocharda, M. Le Pennecc $\square$ dan G. Le Moullaca. 2011. Calcein staining of calcified structures in pearl oyster Pinctada margaritifera and the effect of food resource level on shell growth. Aquaculture Article of Press.

Lucas, J. 2008. Environmental Influences. Dalam P. C. Southgate dan J. S. Lucas (Eds.), The pearl oyster. Elsevier, Amsterdam. Hal $187-229$.

Saucedo, P.E., Southgate, P. 2008. Reproduction, Development and Growth. Dalam P. C. Southgate dan J. S. Lucas (Eds.), The pearl oyster. Elsevier, Amsterdam. Hal. 131 186.

Schöne, B.R., J. Fiebif. M. Pfeiffer, R. Gleß, J. Hickson, A. L. A. Johnson, W. Dreyer dan W. Oschmann.
2005. Climate records from a bivalved Methuselah (Arctica islandica, Mollusca; Iceland). Palaeogeography, Palaeoclimatology, Palaeoecology 228 (2005) $130-148$.

Snow, M.R. dan A. Pring. 2005. The mineralogical microstructure of shells: PART 2. The iridescence colors of abalone shells. American Mineralogist, Volume 90, pages 1705-1711, 2005.

Southgate, P. C., E. Starck, A. Hart, K. T. Wada, M. Monteforte, M. Cariño, S. Langy, C. Lo, H. Acosta-Salmón dan A. Wang. 2008. Exploitation and Culture of Major Commercial Species. Dalam P. C. Southgate dan J. S. Lucas (Eds.), The pearl oyster. Elsevier, Amsterdam. Hal 303-356.

Strack, E. 2008. Introduction of Pearl Oyster. Dalam P. C. Southgate dan J. S. Lucas (Eds.), The pearl oyster. Elsevier, Amsterdam. Hal 1-35.

Strack, E., 2006. Pearls. RuhleDiebener-Verlag, Stuttgart, Germany, 707 hal.

Taylor, J. dan E. Strack. 2008. Pearl Production. Dalam P. C. Southgate dan J. S. Lucas (Eds.), The pearl oyster. Elsevier, Amsterdam. Hal 273-302

Wada, K. T. dan I. Tëmkin. 2008. Taxonomy and Phylogeny. Dalam P. C. Southgate dan J. S. Lucas (Eds.), The pearl oyster. Elsevier, Amsterdam. Hal 37-75.

Yukihira, H., D. W. Klumpp dan J. S. Lucas. 1999. Feeding Adaptations Of The Pearl Oysters Pinctada margaritifera And P. maxima To Variations In Natural Particulates. Mar Ecol Prog Ser ol. 182: 161173,1999. 